\title{
The effects of farming and birth order on asthma and allergies
}

\author{
C. Zekveld*, I. Bibakis", V. Bibaki-Liakou\#, A. Pedioti" , I. Dimitroulis*, J. Harris*, \\ A.J. Newman Taylor* and P. Cullinan*
}

ABSTRACT: A farm childhood is apparently protective in allergic disease, but studies of this issue in Europe have been confined to particular types of farming practice. This study addressed whether or not this effect was generalisable.

A cross-sectional survey of $\mathbf{8 0 0}$ schoolchildren living in rural Crete was undertaken. Standard questions relating to allergic disease were included and atopy was measured through skin-prick tests involving 10 local aeroallergens.

The prevalence of atopy was $24 \%$, but associated symptoms were far less common. At all ages, children from farming families had more frequent contact with farm animals (mainly goats), but were no less likely to be atopic. Atopy and seasonal rhinitis were significantly and independently more common among first-born children.

This community has an intermediate prevalence of atopy but a very low frequency of allergic disease; farming does not seem to be an important determinant, possibly because it is of the wrong sort. Thus farming effects may be specific to local practices. First-born children in this community also appear to be at increased risk of allergic disease.

\section{KEYWORDS: Allergic disease, atopy, birth order, farming, Greece}

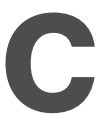

hildhood asthma and allergic disease are distributed unevenly across Europe, with a decreasing prevalence from north to south and from west to east [1]. The reasons for this variation are unclear but are often, if loosely, attributed to westernisation, in itself perhaps a reflection of lower rates of microbial contact in early childhood, leading to inappropriate regulation of a developing immune system. In keeping with this, several studies have reported that European children brought up against a farming background have lower risks of atopy and some associated allergic diseases, particularly hay fever $[2,3]$. Also widely reported is the observation that children from small sibships show increased risk of such allergies, a phenomenon consistent with a protective effect of early infection [4].

For the most part, studies that have examined farming have involved children living in communities in which cows are kept, often in close proximity to the family home. Farming on Crete, an Eastern Mediterranean island, is very different from that in Central and Northern Europe. Cows are absent from the island, and, where livestock are kept, they are invariably goats or sheep, put out to graze on distant mountain slopes; animals are not kept in barns. Arable farming is of olives, vegetables or citrus fruits. For the most part, farmers live in villages some distance from their land. The distinction between farmers and their nonfarming neighbours is not always clear and villagers who do not consider themselves chiefly to be farmers frequently have a small plot of land and often keep a few animals. In addition, many rural families keep one or two goats in their courtyard at home, frequently accompanied by chickens or caged rabbits. Pet dogs and cats live outside.

In an earlier survey, it was reported that the prevalence of childhood atopy in a rural Cretan city [5]. Among rural children, however, there was no relationship between atopy and parental farming. In order to investigate this further, a second, more detailed cross-sectional survey was designed in order to include children living in a variety of rural settings on the island. In addition to atopy, the rural distribution of allergic symptoms consistent with asthma or hay fever was examined.

\section{METHODS}

In 2001, all schoolchildren aged 7-18 yrs and living in four previously unsurveyed areas of rural Crete were invited to take part in a study of the relationships between atopy or associated community was half that in Iráklion, the capital
AFFILIATIONS

*Dept of Occupational \&

Environmental Medicine, Imperial College School of Medicine (National Heart and Lung Institute) and Royal Brompton Hospital, London, UK.

${ }^{\#}$ Anti-tuberculosis Unit, Venezalion Hospital, Iráklion, Crete, Greece.

\section{CORRESPONDENCE}

P. Cullinan

1b Manresa Road

London

SW3 6LR

UK

Fax: 442073518336

E-mail: p.cullinan@imperial.ac.uk

Received:

February 242005

Accepted after revision:

February 022006

\section{SUPPORT STATEMENT}

This study was supported by Medicor (London, UK) and through the Fifth Framework Programme of the European Community (Brussels, Belgium). 
diseases and a farm upbringing. Ethical approval was obtained from The Scientific Committee at the Venezalion Hospital (Iráklion, Crete) and the Ethics Committee at Royal Brompton and Harefield NHS Trust (London, UK). All parents gave written informed consent.

Parents were asked to complete a questionnaire that elicited information about the respiratory health of their participating children, any siblings and the child's parents. Where possible, questions were translated directly from the International Study of Asthma and Allergies in Childhood (ISAAC) questionnaire [6]. Information was requested about levels of parental education and occupation, and about their children's exposure to and contact with farm animals or pets and consumption of farm milk at three different stages of life: infancy, at 5 yrs of age, and during the past year.

Each child was invited to undergo skin-prick tests, in accordance with the ISAAC protocol, involving a series of 10 common aeroallergens: grass pollen (Mediterranean mix), Parietaria, olive blossom, cat fur, Dermatophagoides pteronyssinus and D. farinae, goat epithelium, Cladosporium, cockroach, and poultry, all purchased from ALK Abelló (Hungerford, UK). The negative and positive controls were saline and histamine respectively. A skin-prick test result was considered positive if it produced a mean weal diameter of $\geqslant 3 \mathrm{~mm}$ greater than that produced by the saline control.

\section{Statistical analysis}

Complete data were available for 797 children, 93\% of those eligible. Children were categorised as atopic if they gave one or more positive immediate skin-prick test results. In order to permit comparison with the earlier survey in Crete, a further category (standard atopy), defined by the presence of one or more positive test results to any of the three pollens, either dust mite or cat fur, was formed. Children were considered to suffer from current seasonal rhinitis when they were reported to have had a runny or blocked nose (while not having a cold or influenza) over the past year during the months of March to September. Parents were defined as full-time farmers if either was a full-time farmer; part-time farming indicated that either parent was a part-time farmer but neither was involved fulltime. Only when neither the father nor the mother was involved in any kind of farming was the child considered to come from a nonfarming family.

All information was entered on to a computer database, and analyses were performed after data checking and cleaning. The Pearson Chi-squared test was used to test for associations between categorical variables, and the medians of continuous variables were compared between groups by means of the Kruskal-Wallis or Mann-Whitney test. Where appropriate, Cuzick's trend test was used for ordered exposure variables.

Explanatory variables associated with the outcome of interest $(\mathrm{p}<0.15)$ were included in multivariate logistic regression models and adjusted for those factors that either were significantly associated with atopy or confounded the association between atopy and the main exposure of interest. Effect modification was assessed between the variables retained in the final models.

\section{RESULTS}

Comparisons between farming and nonfarming households A minority $(14 \%)$ of the children were currently living in a nonfarming home; equal proportions of the remainder were from full- or part-time farming families (table 1). Almost all (95\%) current full-time farmers, but only $30 \%$ of part-time farmers and $8 \%$ of current nonfarmers reported that farming was their primary occupation at the time their child was born.

The distributions of age and sex of the surveyed children did not differ across the three levels of farming. Levels of parental education, conversely, varied systematically, with mothers and fathers who farmed having completed fewer years of schooling than other parents $(\mathrm{p}<0.005$ for both). Children from nonfarming households tended to be from smaller families and were more often the first-born. These differences were significant. Reported asthma is rare in this community but was more common in the siblings of those children whose parents were farmers. This difference was not apparent for seasonal rhinitis, reported by $5.9 \%$ of the total population. Parents who were current full-time farmers almost always reported that their primary occupation at the time of their child's birth was farming. Children from farming homes, either full- or part-time, were more likely to have current contact with sheep or goats and live in a home where these animals were kept in close proximity. This was also the case during infancy, at age 5 yrs (data not shown) and for all species of farm animals (goats, sheep, chickens, pigs and rabbits; data shown only for goats/sheep). Of children who currently lived in a home where goats or sheep were kept in the courtyard, 53\% were reported to have daily contact with the animals, 35\% weekly contact and $13 \%$ no contact. During infancy, these proportions were reversed: 24,18 and $58 \%$, respectively.

\section{Atopy, allergic disease and farming}

Of the children, $24 \%$ were atopic; $19 \%$ showed standard atopy (table 1). These frequencies were the same in each of the four study areas. Atopic children were most often sensitised to $D$. pteronyssinus $(12 \%$ of all children) or cockroach $(10 \%)$; prevalences of positive tests to $D$. farinae, any pollen or cat fur were $3-6 \%$. Of the children, $<1 \%$ tested positive to any of the remaining allergens. Symptoms of allergic diseases were far less common than atopy. Only $10(1 \%)$ children were both atopic and wheezy over the past year, and just $15(2 \%)$ had seasonal rhinitis and a positive skin-prick test result for one of the three pollens.

None of these outcomes were obviously related to habitation in a farming home. When separate allergens were examined, the prevalence of cat fur sensitisation was almost three times higher among nonfarming children (9 versus 4 and 3\% for fulland part-time farming children, respectively; ptrend $=0.06$ ). Only children from full-time farming families were sensitised to Cladosporium (2\%). Furthermore, neither atopy nor current wheeze was associated with the frequency of consumption of home-produced milk, boiled or otherwise, during any stage of the child's upbringing (data not shown).

Children with regular animal contact, at any stage of life, were equally likely to be atopic or have current wheeze than children with less frequent or no contact (table 2). Conversely, children who currently lived in homes where sheep or goats 
TABLE 1 Demography, farm animal exposures currently and in infancy, and allergic outcomes by current parental farming

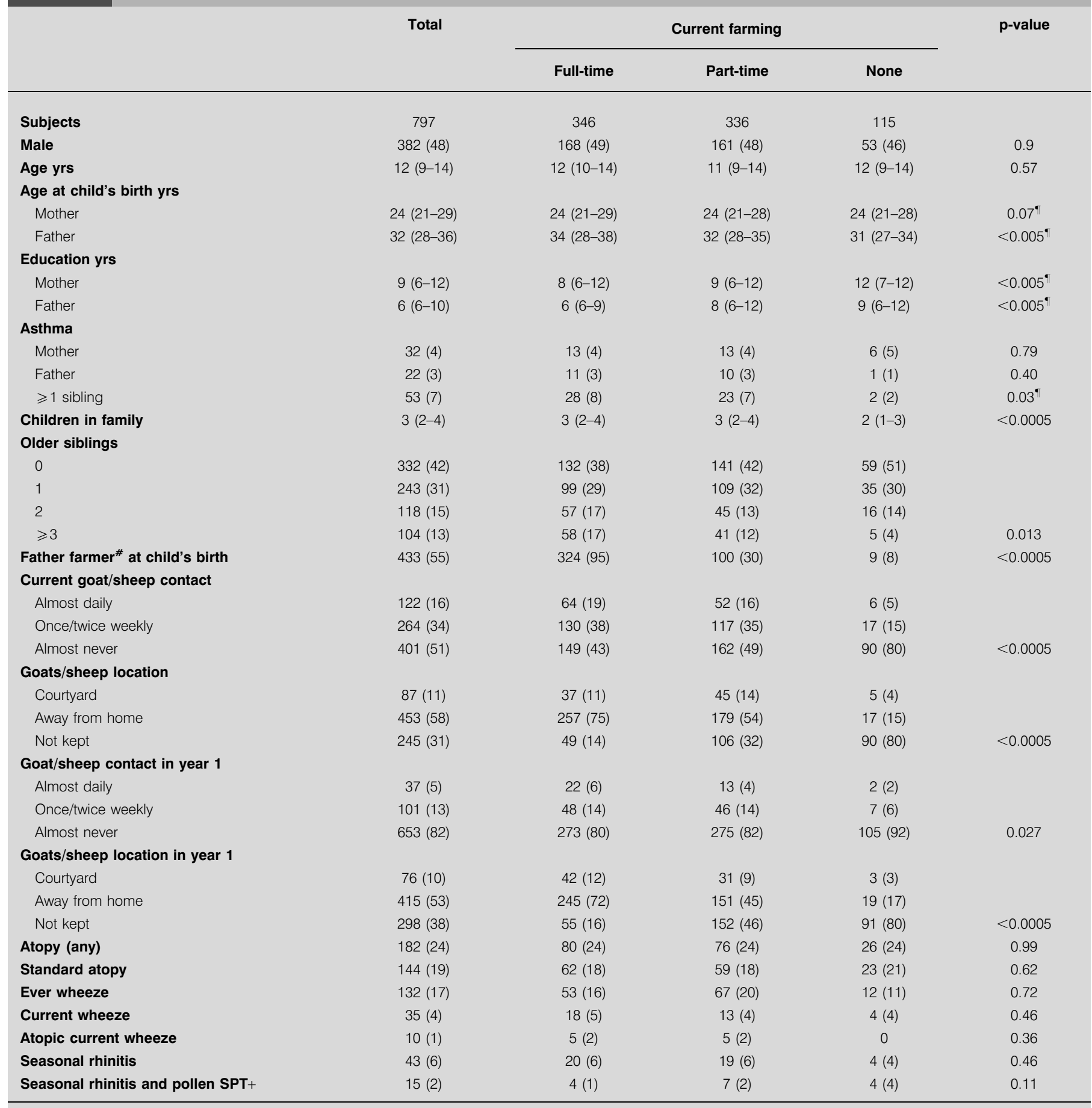

Data are presented as $n, n(\%)$ or median (interquartile range). SPT+: skin-prick test positive. ${ }^{\#}$ : primary occupation; " ${ }^{\natural}$ trend.

were kept nearby were less likely to be atopic $(p=0.01)$, although they had an equal prevalence of current wheeze. Children who lived in a home where goats or sheep were kept in the courtyard during either of the two earlier periods of life were also less often atopic, although these associations could easily have arisen by chance.

\section{Birth order}

Of the children, $42 \%$ were the first-born (table 3 ). They were older, albeit not greatly so, than other children but no more likely to be male. Unsurprisingly, mothers and fathers of firstborn children were younger at the time of their child's birth. Mothers with three or more children had received significantly 
TABLE 2 Prevalence of atopy and current wheezing by animal exposure during three periods of life

\begin{tabular}{|c|c|c|c|c|c|c|}
\hline & \multicolumn{2}{|c|}{ Infancy } & \multicolumn{2}{|c|}{ Age 5 yrs } & \multicolumn{2}{|c|}{ Current year } \\
\hline & Atopy & Current wheeze & Atopy & Current wheeze & Atopy & Current wheeze \\
\hline \multicolumn{7}{|l|}{ Animal contact } \\
\hline \multicolumn{7}{|l|}{ Sheep/goats } \\
\hline Daily & $12(33)$ & $3(8)$ & $23(27)$ & $7(8)$ & $23(24)$ & $5(4)$ \\
\hline ptrend & 0.49 & 0.65 & 0.65 & 0.10 & 0.83 & 0.65 \\
\hline \multicolumn{7}{|l|}{ Chickens } \\
\hline Daily & $9(24)$ & $2(5)$ & $25(25)$ & $8(8)$ & $26(21)$ & $5(4)$ \\
\hline Weekly & $20(23)$ & $2(2)$ & $52(21)$ & $13(5)$ & $62(23)$ & $13(5)$ \\
\hline Never & $150(23)$ & $31(5)$ & $103(25)$ & $14(3)$ & $90(25)$ & $16(4)$ \\
\hline ptrend & 0.99 & 0.63 & 0.68 & 0.04 & 0.42 & 0.93 \\
\hline Never & $163(24)$ & $31(4)$ & $139(25)$ & $20(3)$ & $118(24)$ & $20(4)$ \\
\hline ptrend & 0.93 & 0.95 & 0.26 & 0.07 & 0.60 & 0.65 \\
\hline \multicolumn{7}{|l|}{ Animal location } \\
\hline \multicolumn{7}{|l|}{ Sheep/goats } \\
\hline Courtyard & $13(17)$ & $5(7)$ & $16(18)$ & $4(5)$ & $12(14)$ & $5(6)$ \\
\hline Away from home & $95(24)$ & $11(3)$ & $102(24)$ & $11(3)$ & $100(23)$ & $14(3)$ \\
\hline Not kept & $70(25)$ & $19(6)$ & $62(25)$ & $19(7)$ & $66(28)$ & $15(6)$ \\
\hline ptrend & 0.24 & 0.26 & 0.25 & 0.04 & 0.01 & 0.38 \\
\hline \multicolumn{7}{|l|}{ Chickens } \\
\hline Courtyard & $28(22)$ & $8(6)$ & $32(23)$ & $9(7)$ & $31(22)$ & $12(8)$ \\
\hline Away from home & $82(23)$ & $13(4)$ & $88(23)$ & $16(4)$ & $91(23)$ & $12(3)$ \\
\hline Not kept & $69(24)$ & $14(5)$ & $60(25)$ & $10(4)$ & $54(25)$ & $9(4)$ \\
\hline
\end{tabular}

Data are presented as $n(\%)$, unless otherwise indicated.

fewer years of education ( $\mathrm{ptrend}=0.02$ ). Reported parental asthma and allergies showed no association with birth order.

Atopy was more prevalent (ptrend=0.01) amongst the first-born children, but there were no differences at higher birth orders. Similar results were observed for standard atopy (ptrend $=0.02$ ). Of the remaining outcomes, only seasonal rhinitis ( $p$ trend $=0.07$ ) and seasonal rhinitis accompanied by a positive skin-prick test result for pollen were associated with birth order $(\mathrm{ptrend}=0.01)$.

Logistic regression analysis of the birth order association indicated three independent determinants of atopy: male sex (odds ratio (OR) 2.3, 95\% confidence interval (CI) 1.6-3.2; $\mathrm{p}<0.0005$ ), age (OR 1.06, 95\% CI 1.0-1.13. $\mathrm{yr}^{-1} ; \mathrm{p}=0.07$ ) and first-born birth order (OR 1.68, 95\% CI 1.2-2.4; $\mathrm{p}=0.003$ ).

\section{DISCUSSION}

Childhood atopy, as measured by response to skin-prick testing, is not uncommon in this rural Cretan community.
Symptoms consistent with associated allergic disease, conversely, are rarely reported. Despite clear differences in their contact with farm animals at all ages, no consistent differences in the rates of atopy and allergic disease were found between those children whose parents were or were not farmers. Children who live in houses where goats or sheep are kept adjacent to the home were significantly less often atopic (but not wheezy); given the large number of statistical tests carried out, this finding may have occurred by chance. Atopy was more common among first-born children, an association independent of the other variables measured.

Several explanations were considered for the apparent lack of a protective effect of a farm upbringing in this population. First is the possibility that a rural childhood in Crete is such that every child receives sufficient exposure to the protective factor(s), and that, in this setting, a categorisation by parental farming status is insufficiently discriminatory. Table 4 summarises seven earlier farming studies in which childhood 
TABLE 3 Demographics and outcomes by number of older siblings

\begin{tabular}{|c|c|c|c|c|c|c|}
\hline & Total & 0 & 1 & 2 & $\geqslant 3$ & p-value \\
\hline Subjects & 797 & 332 & 243 & 118 & 104 & \\
\hline \multicolumn{7}{|l|}{ Variable } \\
\hline Male & 382 & $168(51)$ & $115(47)$ & $47(40)$ & $52(50)$ & 0.23 \\
\hline Mother & $24(21-29)$ & $22(20-27)$ & $24(21-28)$ & $26(22-30)$ & $28(25-33)$ & $<0.005^{\#}$ \\
\hline Father & 32 (28-36) & $30(26-35)$ & $32(28-35)$ & 33 (29-38) & $37(34-41)$ & $<0.005^{\#}$ \\
\hline \multicolumn{7}{|l|}{ Education yrs } \\
\hline Mother & $9(6-12)$ & $9(6-12)$ & $9(6-12)$ & $9(6-12)$ & $6(6-12)$ & 0.02 \\
\hline Father & $6(6-10)$ & $6(6-10)$ & $7(6-12)$ & $7(6-11)$ & $6(6-9)$ & 0.11 \\
\hline Atopy (any) & $182(24)$ & $94(30)$ & $46(19)$ & $22(20)$ & $20(20)$ & 0.01 \\
\hline Standard atopy & $144(19)$ & $74(23)$ & $38(16)$ & $16(14)$ & $16(16)$ & 0.02 \\
\hline Ever wheeze & $132(17)$ & $52(16)$ & $41(17)$ & $22(19)$ & $17(16)$ & 0.72 \\
\hline Current wheeze & $35(4)$ & $11(3)$ & $16(6)$ & $4(3)$ & $4(4)$ & 0.85 \\
\hline Atopic current wheeze & $10(1)$ & $4(1)$ & $4(1)$ & $1(1)$ & $1(1)$ & 0.76 \\
\hline Seasonal rhinitis & $43(6)$ & $24(8)$ & $11(5)$ & $5(5)$ & $3(3)$ & 0.07 \\
\hline Seasonal rhinitis and pollen SPT+ & $15(2)$ & $13(4)$ & $1(0.4)$ & $0(0)$ & $1(1)$ & 0.01 \\
\hline
\end{tabular}

Data are presented as $n, n(\%)$ or median (interquartile range). SPT+: skin-prick test positive. ${ }^{\#}$ : trend.

atopy was assessed through use of skin-prick tests along with the present findings, using comparable age groupings where possible. Among children aged 7-8 yrs, the prevalence of atopy in the children of Cretan farmers was far higher than that among farming children in Austria [7] but not dissimilar to estimates among farming children living in Sweden, Australia or Finland [8, 11, 12]. Conversely, the prevalence of atopy among children of nonfarmers in Crete is consistently lower than that among similar children living in any of the other communities studied. Responses to the present questionnaire suggest that children of farming parents in Crete received systematically greater exposure to all farm animals at every stage of life, but, unlike in other studies [9-12], no systematic evidence of any association between animal contact and the frequency of atopy could be found. Thus, the present authors think it improbable that there is a universal protective factor in this rural population.

A second explanation lies in the design of the present survey. Although primary education is essentially universal on Crete, an estimated $5 \%$ of rural children leave school at the age of 12 yrs. Many of these take work in farming, often as goatherds. No differences were found between farm and nonfarm children aged $<12$ yrs, but it is conceivable that there is a small population of older children, missed through the present method of recruitment, who have both an intense farm exposure and a low prevalence of atopy.

A third, and perhaps most plausible, explanation is that farming of this type is indeed not protective. To date, all reports of a low prevalence of allergic respiratory disease in farm children have been in communities in which cows (primarily) are kept and, for part of the year at least, housed in barns close to the family home. In these communities, the consumption of home-produced milk, often unpasteurised, is common. On Crete, in contrast, no cows are farmed and animals are kept outdoors throughout almost the entire year; moreover, goat's milk is universally boiled before it is drunk, being otherwise considered unpalatable. Thus, a childhood farm exposure there is probably different both qualitatively and quantitatively. If this is the case, then it may provide important clues as to the specificity of the protective farm effect observed elsewhere. Following the ecological observation that a protection against atopy in Australian children of farmers is confined to those living in a region in which livestock are commonly kept, Downs et al. [11] suggested that regional differences (perhaps in climate or soil type) may be relevant, or that nonanimal (in that case, cows or sheep) farms do not confer protection.

Although a high prevalence of atopy was found, the present findings suggest that current symptomatic allergic disease, atopic asthma or hay fever, is uncommon in this community, although the frequency of "ever wheeze" was high. Since the present assessment of clinical disease was based on parental responses to a self-completed questionnaire, some caution should be exercised in the interpretation of these observations. There are, with little doubt, important cultural and linguistic influences that determine symptom reporting and it may be that these are, at least in part, responsible for the apparently 
TABLE 4 Studies of childhood atopy, as determined by skin-prick testing (SPT), in farming/nonfarming populations

\begin{tabular}{|c|c|c|c|c|c|c|c|c|c|}
\hline \multirow[t]{2}{*}{ First author [Ref.] } & \multirow{2}{*}{$\begin{array}{l}\text { Age } \\
\text { yrs }\end{array}$} & \multirow{2}{*}{$\begin{array}{c}\text { SPT allergens } \\
n\end{array}$} & \multicolumn{3}{|c|}{ Atopy } & \multicolumn{3}{|c|}{ Current wheeze } & \multirow[t]{2}{*}{ Country } \\
\hline & & & FT farming & PT farming & Nonfarming & FT farming & PT farming & Nonfarming & \\
\hline HORAK [7] & $7-8$ & 7 & 6 & 11 & 26 & & & & Austria \\
\hline KLINTBERG [8] & $7-8$ & 15 & 31 & & 33 & 8 & & 13 & Sweden \\
\hline RiedLeR [9] & $8-10$ & 7 & 19 & & 33 & 5 & & 8 & Austria \\
\hline Remes [12] & $6-13$ & 6 & 28 & & 40 & & & & Finland \\
\hline ERNSt [13] & $12-19$ & 24 & 41 & & 53 & 17 & & 25 & Canada \\
\hline Present survey & $7-8$ & 10 & 24 & 18 & 15 & 9 & 8 & 7 & Crete, Greece \\
\hline Present survey & $8-10$ & 10 & 23 & 17 & 17 & 7 & 4 & 7 & Crete, Greece \\
\hline Present survey & $7-12$ & 10 & 23 & 20 & 24 & 4 & 4 & 5 & Crete, Greece \\
\hline Present survey & $12-18$ & 10 & 25 & 27 & 25 & 5 & 4 & 0 & Crete, Greece \\
\hline
\end{tabular}

Data are presented as \%, unless otherwise indicated. FT: full-time; PT: part-time.

low prevalence of disease in Crete. The English word wheeze, for example, has only an approximate equivalent in Greek. However, a similar dissociation between atopy and allergic disease has been observed elsewhere in South-East Europe [14] and further afield [15]; it may represent a transitional stage between populations with low frequencies of atopy and disease and those with high frequencies of both, such as in North-West Europe. In turn, these may reflect gradations in important causative or protective environmental exposures. The present authors suggest that the high frequency of "ever wheeze" reflects the probable high incidence of early respiratory infection, a pattern common among rural communities in many parts of the world.

Children in the present population who were first-born showed significantly increased rates of atopy and seasonal rhinitis, an association that was independent of the other factors examined. No differences were observed between children of lower birth orders. Similar observations have often been made previously, but, for the most part, in communities with high overall frequencies of childhood allergic disease. If it is argued that the lack of a farming effect in rural Crete is due to every child receiving sufficient exposure to a putative protective and probably microbial factor, then an additional explanation is required for the observed birth order effect. There is now increasing evidence that it may be determined before birth and perhaps reflect pregnancy-related changes in maternal immunity [16-18].

In several but not all respects, the observations reported here confirm those made in an earlier study [5], in which parental farming did not explain apparently lower rates of atopy among children living in rural Crete than those living in the capital city. One important difference is that the prevalence of rural atopy in the present study is approximately twice that measured 3 yrs previously in a different, but not distant, part of the island. The rate reported here was unvarying over four separate districts, which suggests that it is a valid estimate for the rest of the island. It is possible that the original study area had a peculiarly low prevalence of atopy, in which case further study there would be valuable. Alternatively, there has been a sharp increase in the frequency of atopy among children in rural Crete. Although the interval for this seems implausibly short, a similar increase over a similar period was observed among children living in Leipzig, Germany [19]. There, the rise was attributed tentatively to (unidentified) changes consequent on the reunification of Germany; no such major events have been apparent in Crete.

\section{ACKNOWLEDGEMENTS}

The current authors are very grateful to the families and schools who took part in the present survey; and to the fieldworkers from Iráklion (Greece) and London (UK) who made the study possible.

\section{REFERENCES}

1 Anon. Worldwide variation in prevalence of symptoms of asthma, allergic rhinoconjunctivitis, and atopic eczema: ISAAC. The International Study of Asthma and Allergies in Childhood (ISAAC) Steering Committee. Lancet 1998; 351: 1225-1232.

2 Braun-Fahrlander C, Riedler J, Herz U, et al. Environmental exposure to endotoxin and its relation to asthma in school-age children. N Engl J Med 2002; 347: 869-877.

3 Riedler J, Braun-Fahrlander C, Eder W, et al. Exposure to farming in early life and development of asthma and allergy: a cross-sectional survey. Lancet 2001; 358: 1129-1133.

4 Karmaus W, Botezan C. Does a higher number of siblings protect against the development of allergy and asthma? A review. J Epidemiol Community Health 2002; 56: 209-217.

5 Barnes M, Cullinan P, Athanasaki P, et al. Crete: does farming explain urban and rural differences in atopy? Clin Exp Allergy 2001; 31: 1822-1828.

6 Asher MI, Keil U, Anderson HR, et al. International Study of Asthma and Allergies in Childhood (ISAAC): rationale and methods. Eur Respir J 1995; 8: 483-491.

7 Horak F Jr, Studnicka M, Gartner C, et al. Parental farming protects children against atopy: longitudinal evidence 
involving skin prick tests. Clin Exp Allergy 2002; 32: 1155-1159.

8 Klintberg B, Berglund N, Lilja G, Wickman M, HageHamsten M. Fewer allergic respiratory disorders among farmers' children in a closed birth cohort from Sweden. Eur Respir J 2001; 17: 1151-1157.

9 Riedler J, Eder W, Oberfeld G, Schreuer M. Austrian children living on a farm have less hay fever, asthma and allergic sensitization. Clin Exp Allergy 2000; 30: 194-200.

10 Von Ehrenstein OS, Von Mutius E, Illi S, Baumann L, Bohm O, von Kries R. Reduced risk of hay fever and asthma among children of farmers. Clin Exp Allergy 2000; 30: 187-193.

11 Downs SH, Marks GB, Mitakakis TZ, Leuppi JD, Car NG, Peat JK. Having lived on a farm and protection against allergic diseases in Australia. Clin Exp Allergy 2001; 31: 570-575.

12 Remes ST, Iivanainen K, Koskela H, Pekkanen J. Which factors explain the lower prevalence of atopy amongst farmers' children? Clin Exp Allergy 2003; 33: 427-434.
13 Ernst P, Cormier Y. Relative scarcity of asthma and atopy among rural adolescents raised on a farm. Am J Respir Crit Care Med 2000; 161: 1563-1566.

14 Priftanji A, Strachan D, Burr M, et al. Asthma and allergy in Albania and the UK. Lancet 2001; 358: 1426-1427.

15 Yemaneberhan H, Bekele Z, Venn A, Lewis S, Parry E, Britton J. Prevalence of wheeze and asthma and relation to atopy in urban and rural Ethiopia. Lancet 1997; 350: 85-90.

16 Devereux G, Barker RN, Seaton A. Antenatal determinants of neonatal immune responses to allergens. Clin Exp Allergy 2002; 32: 43-50.

17 Harris JM, White C, Moffat S, Mills P, Newman Taylor AJ, Cullinan P. New pregnancies and loss of allergy. Clin Exp Allergy 2004; 34: 369-372.

18 Karmaus W, Arshad SH, Sadeghnejad A, Twiselton R. Does maternal immunoglobulin E decrease with increasing order of live offspring? Investigation into maternal immune tolerance. Clin Exp Allergy 2004; 34: 853-859.

19 Von Mutius E, Weiland SK, Fritzsch C, Duhme H, Keil U. Increasing prevalence of hay fever and atopy among children in Leipzig, East Germany. Lancet 1998; 351: 862-866. 